\title{
Preliminary Analysis of SiC BWR Channel Box Performance under Normal Operation
}

Nuclear Technology

Research and Development

Prepared for U.S. Department of Energy Nuclear Technology Research and Development Advanced Fuels Campaign G. Singh ${ }^{1,2}$, J. Gorton ${ }^{3}$, D. Schappel ${ }^{2}, \mathbf{N}$. R. Brown ${ }^{3}$, Y. Katoh ${ }^{1}$, K. Terrani ${ }^{1}$, and B.

D. Wirth ${ }^{1,2}$

${ }^{1}$ Oak Ridge National Laboratory ${ }^{2}$ University of Tennessee Knoxville ${ }^{3}$ Pennsylvania State University May 17, 2018 M3NT-18OR020205033 



\section{DISCLAIMER}

This information was prepared as an account of work sponsored by an agency of the U.S. Government. Neither the U.S. Government nor any agency thereof, nor any of their employees, makes any warranty, expressed or implied, or assumes any legal liability or responsibility for the accuracy, completeness, or usefulness, of any information, apparatus, product, or process disclosed, or represents that its use would not infringe privately owned rights. References herein to any specific commercial product, process, or service by trade name, trade mark, manufacturer, or otherwise, does not necessarily constitute or imply its endorsement, recommendation, or favoring by the U.S. Government or any agency thereof. The views and opinions of authors expressed herein do not necessarily state or reflect those of the U.S. Government or any agency thereof. 



\section{SUMMARY}

SiC-SiC composites are being considered for applications in the core components, including BWR channel box and fuel rod cladding, of light water reactors to improve accident tolerance. In the extreme nuclear reactor environment, core components like the BWR channel box will be exposed to neutron damage and a corrosive environment. To ensure reliable and safe operation of a SiC channel box, it is important to assess its deformation behavior under in-reactor conditions including the expected neutron flux and temperature distributions. In particular, this work has evaluated the effect of non-uniform dimensional changes caused by spatially varying neutron flux and temperatures on the deformation behavior of the channel box over the course of one cycle of irradiation. These analyses have been performed using the fuel performance modeling code BISON and the commercial finite element analysis code Abaqus, based on fast flux and temperature boundary conditions have been calculated using the neutronics and thermal-hydraulics codes Serpent2 and COBRA-TF, respectively. The dependence of dimensions and thermophysical properties on fast flux and temperature has been incorporated into the material models. These initial results indicate significant bowing of the channel box with a lateral displacement greater than $6.5 \mathrm{~mm}$. The channel box bowing behavior is time dependent, and driven by the temperature dependence of the SiC irradiation-induced swelling and the neutron flux/fluence gradients. The bowing behavior gradually recovers during the course of the operating cycle as the swelling of the $\mathrm{SiC}-\mathrm{SiC}$ material saturates. However, the bending relaxation due to temperature gradients does not fully recover and residual bending remains after the swelling saturates in the entire channel box. 
Preliminary Analysis of SiC BWR Channel Box Performance Under Normal Operation 


\section{CONTENTS}

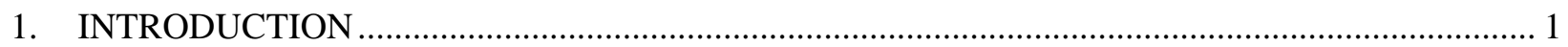

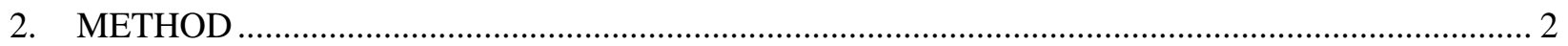

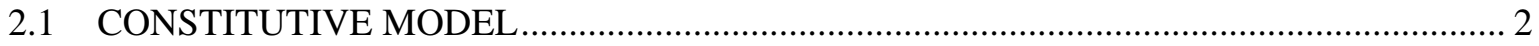

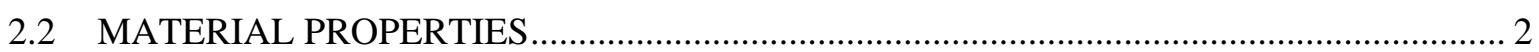

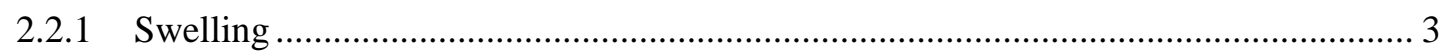

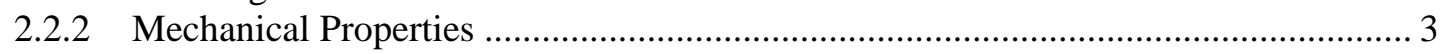

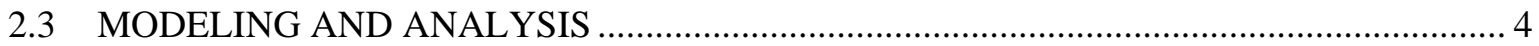

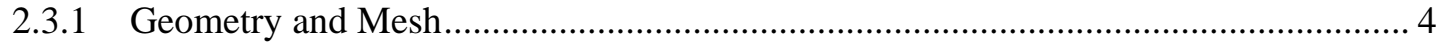

2.3.2 Implementation of Anisotropic Properties................................................................. 4

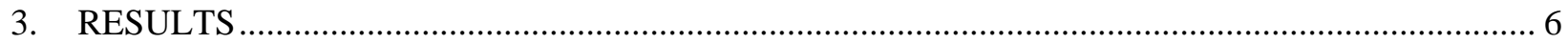

3.1 Neutron Flux and Thermal Boundary Conditions ............................................................. 6

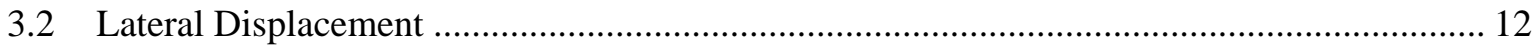

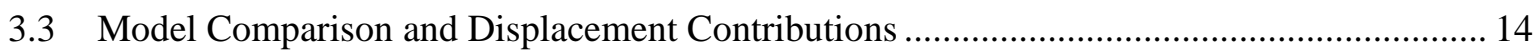

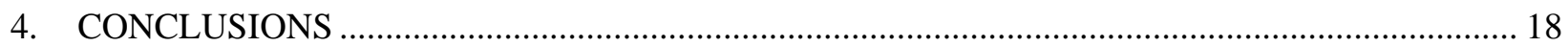

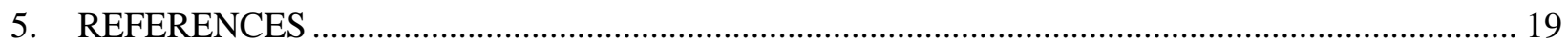

\section{FIGURES}

Figure 1: Swelling as a function of dose at different temperature for CVD SiC; CVI SiC-SiC was assigned same swelling properties [8].

Figure 2: A section of the finite element model of channel box (left) and model showing implementation of anisotropic properties through rotating coordinate system (right). 5

Figure 3: Representation of the radial axis or perpendicular direction to the channel box walls in BISON analysis.

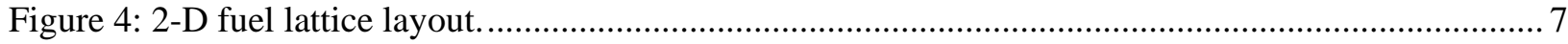

Figure 5: Comparison between experimental and CTF-predicted void fraction as a function of flow quality 8

Figure 6: Axial variation of coolant density in the fuel assembly. ........................................................... 9

Figure 7: Effect of channel box surface roughness on assembly pressure drop. ...................................... 10

Figure 8: Comparison between calculated and reference average axial power profiles. ........................... 10

Figure 9: Spatial temperature distribution of the channel box in Simulation 1.......................................11

Figure 10: Spatial temperature distribution of the channel box in Simulation 2. .................................... 11

Figure 11: Spatial distribution of fast flux in the channel box for Simulation 1...................................... 12

Figure 12: Spatial distribution of fast flux in the channel box for Simulation 2 ..................................... 12 
Figure 13: Displacement (units: meter) of the channel box along x-direction (perpendicular to wall) after 11 days, one month, two months and four months (from left to right). Displacement is exaggerated for visualization purpose. Total displacement shown in Figure 14. 13

Figure 14: Total lateral displacement (in diagonal direction) vs. height of the channel box at different operating times 13

Figure 15: Plots comparing the lateral displacement magnitude predicted by BISON (left) and Abaqus (right)... 15

Figure 16: Plots showing the effect on displacement from thermal expansion, temperature profile, and swelling. Positive difference indicates the effect induced additional lateral displacement, while negative indicates a reduction in displement. 16

Figure 17: Plots showing the effect of the irradiation creep model of SiC on channel box displacement (plots on the left side). The plots on the right side indicate the corresponding differences to the base model. a) and b) Compare the effect of creep using a temperature independent creep constant; c) and d) Compare the effect of creep using a temperature dependent creep constant; and e) and f) Compare the effect of creep using a 100X increase in the creep constant.

\section{TABLES}

Table 1: Dependence of SiC-SiC composite material properties of channel box on irradiation and temperature [17].

Table 2: List of the elastic properties used for the SiC-SiC channel box [21] ......................................... 4

Table 3: Dimensions of the channel box considered in the analysis....................................................... 4

Table 4: Comparison of boundary conditions used in Simulation 1 and Simulation 2............................. 7 


\section{ACRONYMS}

BFBT $\quad$ BWR Full-Size Fine-Mesh Bundle Tests benchmark

BWR Boiling water reactor

CASL Consortium for Advanced Simulation of Light Water Reactors

CMC Ceramic matrix composite

CTF COBRA-TF - thermal hydraulic code for LWR vessel and core analysis

CVD Chemical vapor deposition

CVI Chemical vapor infiltration

dpa Displacement per atom

DOE-NE US Department of Energy Office of Nuclear Energy

ECCS Emergency core cooling system

ESBWR European Simplified Boiling Water Reactor

FE Finite element

FEA Finite element analysis

GE General Electric company

LOCA Loss of coolant accident

LWR Light water reactor

PARCS Purdue Advanced Reactor Core Simulator code

PWR Pressurized water reactor

$\mathrm{SiC} \quad$ Silicon Carbide

SiC-SiC Silicon carbide fiber-reinforced silicon carbide matrix composite 



\section{PRELIMINARY ANALYSIS OF SIC BWR CHANNEL BOX PERFORMANCE UNDER NORMAL OPERATION}

\section{INTRODUCTION}

The 2011 Fukushima Daiichi nuclear power plant accident strongly stressed the need to develop accident tolerant fuel and core materials to withstand harsh accident scenarios, including the beyonddesign-basis accident of Fukushima, as well as loss of coolant accidents. During a typical loss of coolant accident (LOCA), a substantial amount of heat is generated even after the reactor scram. If the emergency core cooling system (ECCS) is not operational then the temperature of the core rises quickly and can lead to core meltdown and ultimately to a beyond-design-basis accident as happened in Fukushima Dai-ichi in 2011. The Fukushima Dai-ichi nuclear power plant accident strongly emphasizes the need for passively safe reactor designs that resist severe degradation under beyond-design-basis accident conditions.

During a LOCA scenario, significant physical and chemical degradation of the reactor core components begins when the temperature approaches $800^{\circ} \mathrm{C}$. At temperatures greater than $1200{ }^{\circ} \mathrm{C}$, Zircaloy reacts with steam in an exothermic reaction to produce zirconium dioxide and hydrogen [1, 2]. The heat generated due to the reaction between steam and the many tons of Zircaloy in the core can be as large as ten times the decay heat, leading to a further temperature increase. The high temperatures lead to partial to complete core meltdown and the generated hydrogen can compromise the containment through pressurization and explosive recombination with oxygen. As part of the efforts to enhance the accident tolerance of the reactors, the viability of silicon carbide fiber reinforced silicon carbide ceramic matrix ( $\mathrm{SiC}-\mathrm{SiC}$ ) composites for channel boxes is being assessed under several research programs around the world [3]. SiC-SiC ceramic matrix composites (CMCs) offer a number of attractive properties which are promising for LWR applications, these include irradiation stability [4], reasonable fracture toughness [5], the ability to maintain mechanical properties and chemical inertness at elevated temperatures, and exceptional resistance to steam oxidation up to at least $1700^{\circ} \mathrm{C}[6,7]$. A comprehensive discussion on the properties of SiC-SiC is provided in Ref. [8].

The channel box, a thin-walled, core-length square box surrounding the fuel bundle, provides mechanical-structural stability to the core, provides hydraulic separation of the BWR fuel assemblies from the large, low pressure-drop space in-between assemblies, and physically separates the BWR fuel bundles from the control blade and instrumentation tubes [9]. SiC-SiC composites undergo temperature dependent swelling [8] under neutron irradiation. It has been shown that non-uniform swelling in SiC-SiC fuel cladding may lead to significant lateral bowing [10], and this analysis is meant to evaluate the possibility that similar distortion may occur in SiC-SiC channel box. Significant distortion in the channel box may lead to interference with the control blade. Channel box distortion may also hinder lifting of fuel assemblies through the upper core grid, and decrease the dry-out and LOCA thermal margins. The work presented herein primarily focusses on the distortion of fully SiC-SiC composite channel box for boiling water reactor (BWR) application.

This initial study has been performed using finite element analysis (FEA) of the channel box, based on incorporating thermal and neutronic boundary conditions that exist in a typical BWR in the absence the control blade insertion. The main tools used in predicting the channel box temperature and fast flux boundary conditions are the Consortium for Advanced Simulation of Light Water Reactors (CASL) version of COBRA-TF (CTF) [11] and the VTT Technical Research Centre of Finland code 
Serpent2 [12], respectively. CTF is a thermal hydraulics sub-channel code and was used to create BWR fuel assembly models representative of the GE14 10x10 design with a SiC-SiC channel box. Serpent2 is a Monte Carlo neutron transport code in which 2-D fuel lattice models were developed to predict the neutron flux in the channel box for neutron energies greater than $0.1 \mathrm{MeV}$. The FEA analysis was performed using both the BISON fuel performance code [13] and the commercial FE code Abaqus [14].

\section{METHOD}

\subsection{CONSTITUTIVE MODEL}

SiC-SiC composites undergo swelling due to neutron irradiation. The magnitude of the swelling strain has an inverse temperature dependence, with a larger swelling magnitude observed at lower irradiation temperatures $[8,15]$. This swelling strain $\left(\boldsymbol{\varepsilon}^{\mathrm{s}}\right)$, saturates at around $\sim 1$ displacement per atom (dpa) for irradiation temperatures below about $1000^{\circ} \mathrm{C}$. The non-uniform neutron flux distribution in a SiC-SiC channel box is expected to generate differential swelling across the channel box. The material undergoes irradiation creep $\left(\varepsilon^{c}\right)$ under the influence of stress and irradiation, in addition to thermal strain (also dependent on temperature and stress), which is denoted as $\boldsymbol{\varepsilon}^{\text {th }}$. Besides the swelling, creep and thermal expansion/contraction, the material also undergoes elastic deformation which is represented by the elastic strain $\left(\varepsilon^{\mathrm{e}}\right)$. The total strain consists of a linear combination of the swelling strain, creep strain, thermal strain and elastic strain as shown in equation (1). The stress-strain relationship is based on Hooke's law (equation (2)). Equation (3) represents the iterative updating scheme to calculate stresses in a finite element calculation.

$$
\begin{aligned}
& \boldsymbol{\varepsilon}^{\text {total }}=\boldsymbol{\varepsilon}^{\mathrm{e}}+\boldsymbol{\varepsilon}^{\mathrm{c}}+\boldsymbol{\varepsilon}^{\mathrm{s}}+\boldsymbol{\varepsilon}^{\text {th }} \\
& \boldsymbol{\sigma}=\mathbf{D} \boldsymbol{\varepsilon}^{\mathrm{e}} \\
& \Delta \boldsymbol{\sigma}=\check{\mathbf{D}} \Delta \boldsymbol{\varepsilon}^{\mathrm{e}}+\Delta \mathbf{D} \boldsymbol{\varepsilon}^{\mathrm{e}}
\end{aligned}
$$

In Eqs. (2) and (3), $\mathbf{D}$ is the elastic stiffness matrix and $\check{\mathbf{D}}$ is the mean elastic stiffness matrix during the numerical solution step increment. $\mathbf{D}$ is dependent on neutron fluence and temperature. The next section discusses the material properties.

\subsection{MATERIAL PROPERTIES}

Table 1 provides SiC-SiC composite material properties and their dependence on irradiation dose and temperature, which have been considered in this analysis [16]. The following sub-sections describe the material property implementation in our finite element analysis in greater detail. 
Table 1: Dependence of SiC-SiC composite material properties of channel box on irradiation and temperature [17].

\begin{tabular}{|c|c|c|}
\cline { 2 - 3 } \multicolumn{1}{c|}{} & Temperature dependence & Effect of Irradiation \\
\hline $\begin{array}{c}\text { Coefficient of thermal } \\
\text { expansion }\end{array}$ & Dependent [8] & Negligible [8] \\
\hline $\begin{array}{c}\text { Creep strain } \\
\text { (Irradiation creep } \\
\text { compliance) }\end{array}$ & Dependent [18] & $\begin{array}{c}\text { Irradiation effect phenomena } \\
{[18]}\end{array}$ \\
\hline Swelling strain & Dependent [4, 15] & $\begin{array}{c}\text { Irradiation effect phenomena } \\
{[4,15]}\end{array}$ \\
\hline Specific heat capacity & Dependent & Negligible \\
\hline Thermal conductivity & $\begin{array}{c}\text { Dependent, basis for modeling } \\
\text { exists [8, 15] }\end{array}$ & $\begin{array}{c}\text { Strong effect, basis for } \\
\text { modeling exists [8, 15] }\end{array}$ \\
\hline Elastic constants & $\begin{array}{c}\text { Dependent, basis for modeling } \\
\text { exists [8, 15] }\end{array}$ & Minor effect, known [15] \\
\hline
\end{tabular}

\subsubsection{Swelling}

CVD SiC and CVI SiC-SiC shows very similar swelling properties [19, 20]. Figure 1 plots the variation of swelling with fluence for CVD $\mathrm{SiC}$ as a function of temperature in the low-temperature, swelling saturating regime. In the analysis presented here, the CVI SiC-SiC composites were assumed to have swelling properties that are identical to the response of CVD SiC, shown in Figure 1.

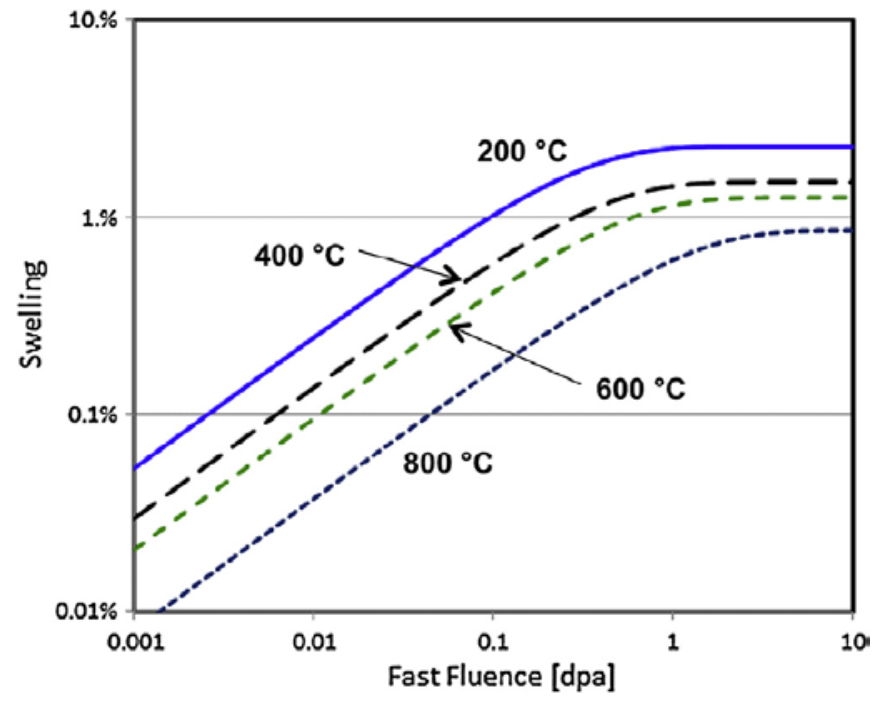

Figure 2: Swelling as a function of dose at different temperature for CVD SiC; CVI SiC-SiC was assigned same swelling properties [8].

\subsubsection{Mechanical Properties}

Anisotropic elastic properties for the SiC-SiC channel box were implemented in both Abaqus and BISON. Table 2 lists the initial values used in these models. The elastic moduli are represented by ' $\mathrm{E}$ ', shear moduli by ' $G$ ' and Poisson's ratio by ' $v$ '. The subscript ' $r$ ' corresponds to the perpendicular direction of the channel box wall, the ' $q$ ' corresponds to the horizontal-parallel direction, and ' $z$ ' corresponds to the vertical direction. 
Table 2: List of the elastic properties used for the SiC-SiC channel box [21].

\begin{tabular}{lll}
\hline $\mathrm{E}_{\mathrm{r}}=80 \mathrm{GPa}$ & $v_{\mathrm{rq}}=0.21$ & $\mathrm{G}_{\mathrm{rq}}=70 \mathrm{GPa}$ \\
$\mathrm{E}_{\mathrm{q}}=205 \mathrm{GPa}$ & $v_{\mathrm{rz}}=0.21$ & $\mathrm{G}_{\mathrm{rz}}=80 \mathrm{GPa}$ \\
$\mathrm{E}_{\mathrm{z}}=205 \mathrm{GPa}$ & $v_{\mathrm{qz}}=0.17$ & $\mathrm{G}_{\mathrm{qz}}=110 \mathrm{GPa}$ \\
\hline
\end{tabular}

Further details of SiC-SiC composite properties and the effect of irradiation and temperature on the properties are provided in Ref. [17] by Singh and co-workers.

\subsection{MODELING AND ANALYSIS}

The SiC-SiC model was implemented in both Abaqus and BISON [17]. Figure 2 shows a representation of the finite element mesh used for a section of the channel box model used in the analysis.

\subsubsection{Geometry and Mesh}

The geometric dimensions for the model were representative of a GE14 BWR assembly [23] and are provided in Table 3. Second order quadrilateral elements with 8 nodes were used to generate the finite element mesh of the channel box model. The mesh consisted of 11600 elements in total, and used 100 elements along the axial direction. In our initial model, the channel box was considered to be free of any external mechanical loads. The bottom position of the channel box was fixed whereas the top of the box was free to deform.

Table 3: Dimensions of the channel box considered in the analysis.

\begin{tabular}{cc}
\hline Geometry & Dimension \\
\hline $\begin{array}{c}\text { Cross-sectional } \\
\text { width }\end{array}$ & $14.02 \mathrm{~cm}$ \\
Wall thickness & $3.05 \mathrm{~mm}$ \\
Height & $3.71 \mathrm{~m}$ \\
$\begin{array}{c}\text { Inner radius of } \\
\text { curvature }\end{array}$ & $8 \mathrm{~mm}$ \\
$\begin{array}{c}\text { Outer radius of } \\
\text { curvature }\end{array}$ & $10 \mathrm{~mm}$ \\
\hline
\end{tabular}

\subsubsection{Implementation of Anisotropic Properties}

Anisotropic properties were implemented through a rotation of the coordinate axes, namely the properties were implemented along the coordinate axes and the axes were rotated at the required locations in the geometric model, as shown in Figure 2. 

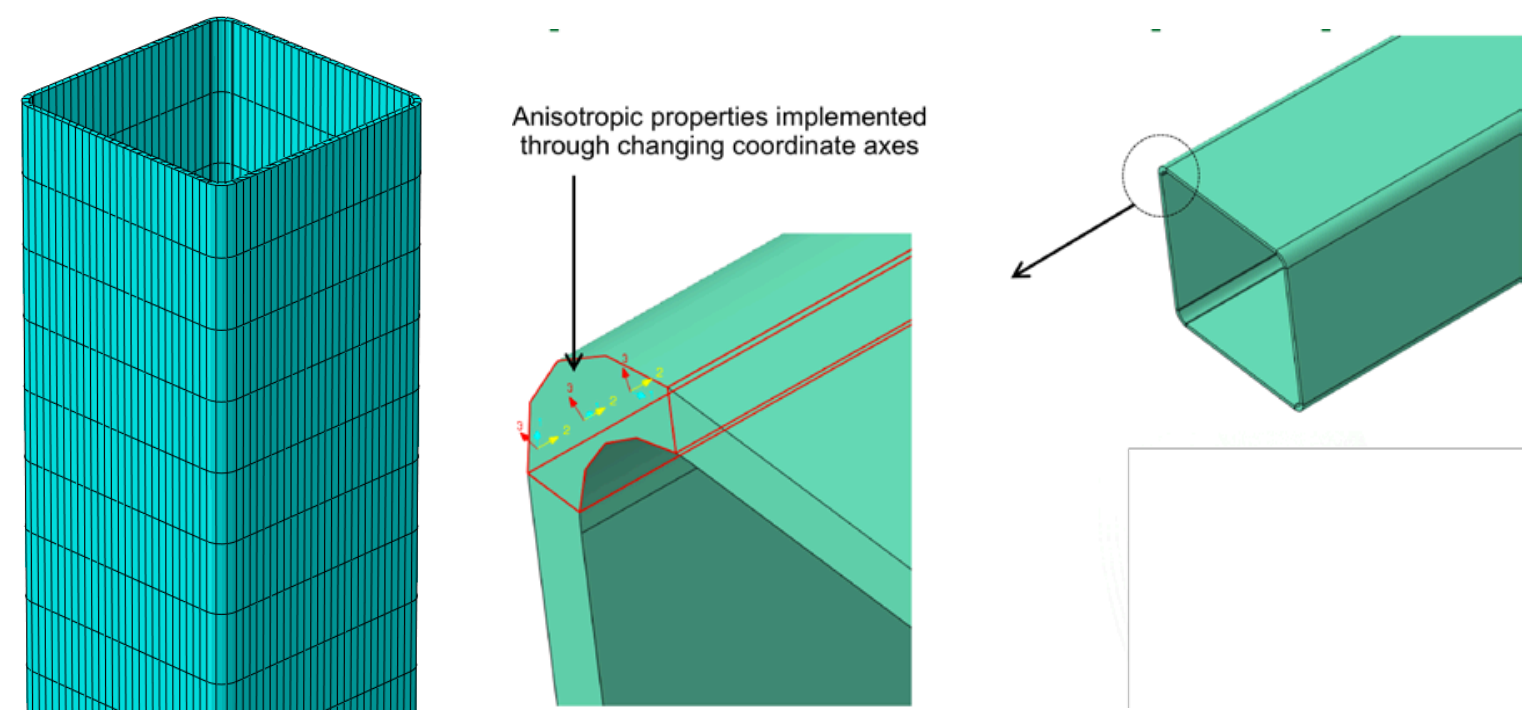

Figure 3: A section of the finite element model of channel box (left) and model showing implementation of anisotropic properties through rotating coordinate system (right).

In Abaqus, the coordinate system was rotated through the built-in feature of defining local coordinate axes using surface topology. The flux and temperature boundary conditions were implemented by projecting the two-dimensional arrays of flux (dimension: 99x20 for height $\mathrm{x}$ width) and temperature (99x11) values onto the wall of each channel box and assigning the value to the element integration points using bilinear interpolation from the arrays. In BISON, the rotation of the coordinate axes was performed using a piecewise method, where the radial axis along the flat walls of the channel box is determined by user set vectors which correspond to the wall surface normal, while the corners are determined by the vector between the mesh quadrature point and its associated center coordinate of the respective corner arc. Thus, the center coordinate for each corner of the channel box corresponds to a separate location. Figure 3 provides a representation of the resulting coordinate rotation for the radial axis. In BISON, the Cartesian axes for the horizontal directions are denoted as $\mathrm{x}$ and $\mathrm{y}$, while the $\mathrm{z}$ axis is defined as the vertical direction. To complete the coordinate rotation, the azimuthal axis was obtained by taking the cross product of the radial and axial axes, which successfully implemented the anisotropic elastic properties and along the rotated coordinate axes. Then neutron flux and temperature profiles, which are based on neutronics and thermal hydraulics calculations, were implemented in the model using bilinear interpolation. 

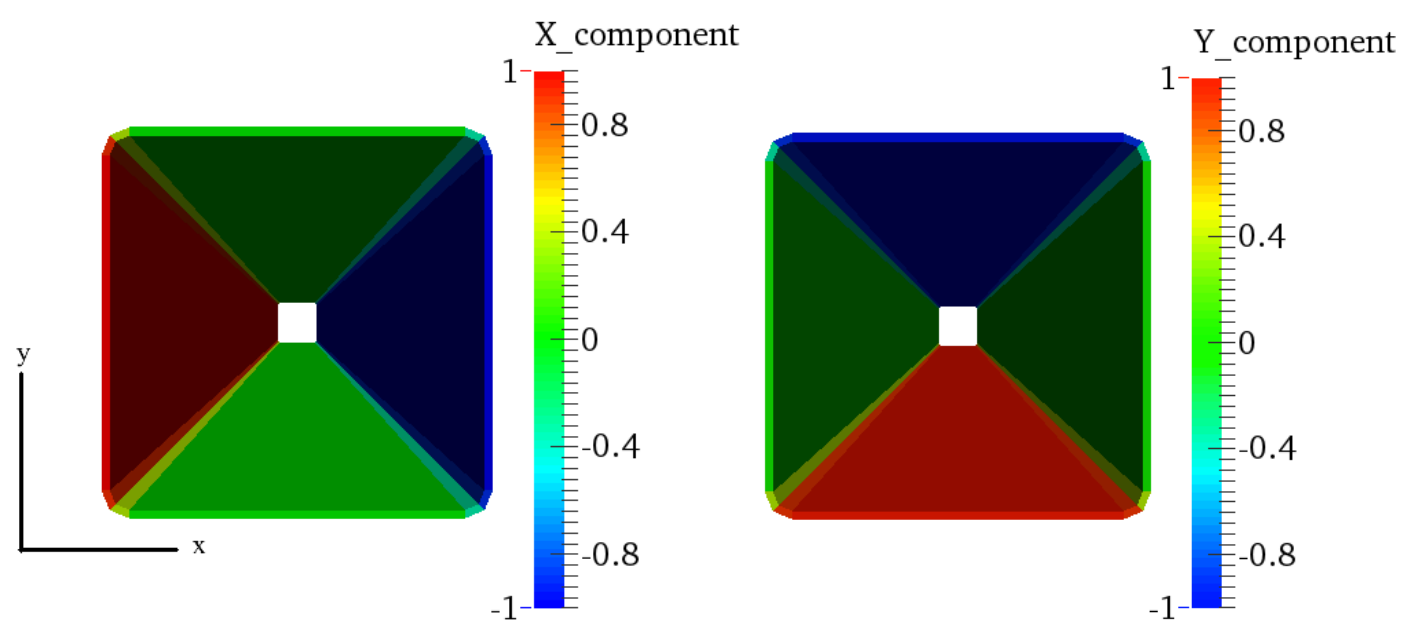

Figure 4: Representation of the radial axis or perpendicular direction within the channel box walls in BISON analysis.

\section{RESULTS}

\subsection{Neutron Flux and Thermal Boundary Conditions}

The neutron fast flux and thermal boundary conditions were calculated using the Serpent2 and CTF neutronics and thermal-hydraulics codes, respectively. Two GE14-like BWR fuel assembly models, referred to as Simulation 1 and Simulation 2, were developed in COBRA-TF (CTF) to predict the temperature distribution in the channel box, with the two models having different boundary conditions. Geometrically, the two models are identical except for slightly different assembly lengths. Due to the proprietary nature of the GE14 design, the geometric design of the models was based on a variety of publicly available sources, such as older BWR/5 designs and hypothetical designs such as the European Simplified Boiling Water Reactor (ESBWR) [22, 23]. For the purpose of calculating the deformation of channel box, presented in this report, boundary conditions generated from Simulation 2 were used.

Each model contains 119 coolant sub-channels, 92 fuel rods, and space for two large water rods. A channel box was created in the models by placing a heat slab structure with thermal properties of nucleargrade SiC-SiC $[8,15]$ around the perimeter of the fuel pin lattice. Default material properties provided in $\mathrm{CTF}$ for $\mathrm{UO}_{2}$ and Zircaloy were used for the fuel and cladding, respectively.

BWR fuel assemblies contain seven or eight spacer grids along the length of the assembly [23], but their design is proprietary. The spacer grids used in the models are based on BFBT 8x8 spacer grids with modified loss coefficients from Glück [24]. All spacer grids in the models have the same loss coefficients, but in reality, the upper-level spacer grids have a different design and are less restrictive because partlength rods do not extend into the upper regions of the assembly [25]. The disappearance of part-length rods is a feature that has not yet been modeled in CTF.

The average axial power profiles for the two models come from different sources, with the Simulation 1 profile obtained from Fensin [26] and the Simulation 2 profile was obtained from Cheng, et al. [27]. The radial heterogeneity in the power and neutron flux is driven by the heterogeneity in the BWR fuel assembly design and comes directly from the detailed lattice physics calculations. A power profile for each rod was generated using fission power detectors in Serpent2 to account for the radial variation of 
power in the assembly. Other boundary conditions, including inlet coolant temperature, system pressure, coolant mass flow rate, and core power for Simulation 1 came from the thesis by Ferroni [23]. The boundary conditions for Simulation 2 are provided by Cheng, et al. [27]. A comparison of the initial conditions is shown in Table 3.

Table 4: Comparison of boundary conditions used in Simulation 1 and Simulation 2.

\begin{tabular}{lcc}
\hline Parameter & Simulation 1 & Simulation 2 \\
\hline Pressure (bar) & 71.36 & 71.43 \\
Inlet Coolant Temperature $\left({ }^{\circ} \mathrm{C}\right)$ & 278.3 & 276.6 \\
Core Coolant Mass Flow Rate $(\mathrm{kg} / \mathrm{s})$ & 13671 & 13671 \\
Total Core Power (MWt) & 3323 & 3988 \\
Full Rod Length (m) & 3.708 & 3.731
\end{tabular}

Seven different 2-D Serpent2 models were created for each simulation and were used to produce relative power profiles for use in the CTF models and to provide a fast flux distribution in the channel box. These seven models are based on the seven distinct axial regions of a BWR fuel assembly as described by Fensin [26]. Each zone is distinguishable by fuel enrichment, gadolinium content, coolant density and void fraction, linear power, and the disappearance of partial length rods in the upper zones. The fuel enrichments and gadolinium content were obtained from Fensin [26], and the coolant density and void fraction and linear power were obtained using an iterative process with the CTF models. Preliminary CTF calculations of power deposition and coolant properties were used in the Serpent models to produce preliminary power profiles. This process was iterated until variations in the model predictions became insignificant.

Geometrically, the 2-D fuel lattices are identical to the geometry used in the CTF models. Since a different model was created for each axial zone, the disappearance of part-length rods was incorporated within the model by simply leaving those lattice sites empty. A 2-D lattice of one of the Serpent2 models is shown in Figure 4.

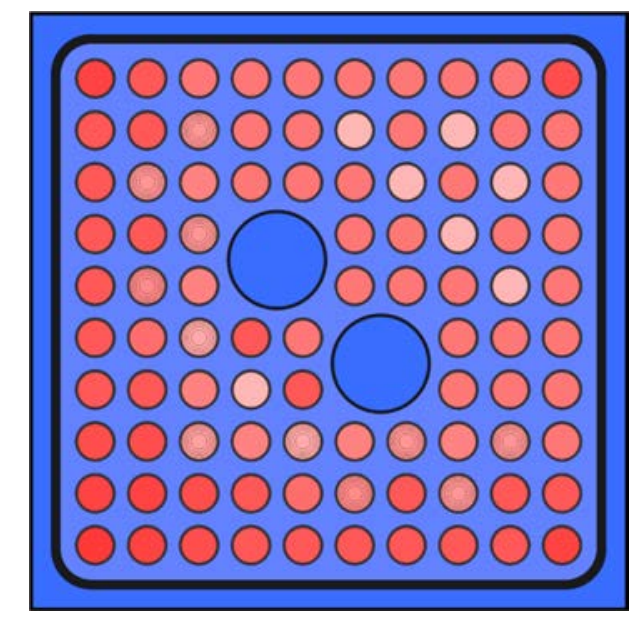

Figure 5: 2-D fuel lattice layout.

\section{Model Verification}

To ensure the accuracy of the models, comparisons were made to data available in the literature pertaining to two-phase flow and boiling in BWRs. Figure 5 compares the CTF-predicted void fraction as 
a function of flow quality to an experiment by Inoue, et al., [28] where void fraction was measured using $\mathrm{X}$-ray scans in a pressurized test loop with an 8 x8 assembly of electrically-heated Inconel rods. All data points in Figure 5 are assembly-averaged.

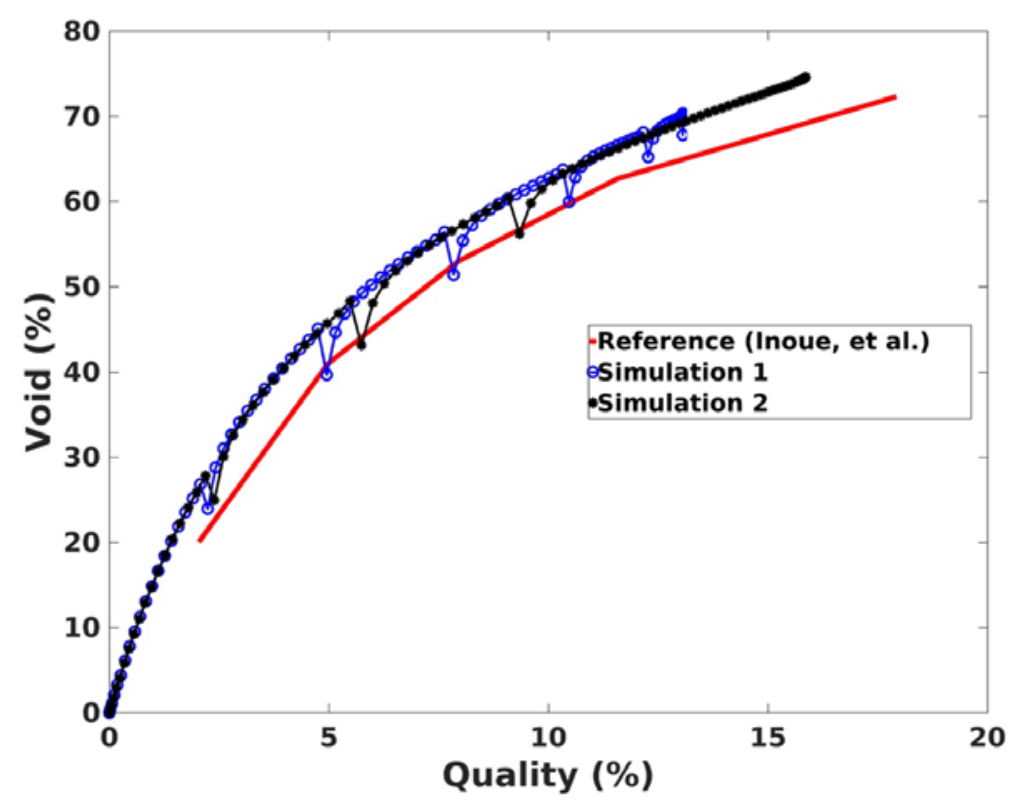

Figure 6: Comparison between experimental and CTF-predicted void fraction as a function of flow quality.

Some differences are expected between the experiment and the CTF simulations because the experiment was conducted at 7.2 MPa and has fewer rods than in the CTF models. Additionally, the experiment had a mass flux of $1988 \mathrm{~kg} / \mathrm{m}^{2}$-s, while the CTF model uses a mass flux of $1930.2 \mathrm{~kg} / \mathrm{m}^{2}$-s based on the core flow rate provided in Table 1 and the flow area of the assembly models. These differences are consistent with the over prediction of void fraction relative to the experimental results shown in Fig. 5. As well, the sharp drops shown in the CTF-predicted void fraction are caused by the sudden flow area restriction imposed by the grid spacers, which were not present in the experiment.

Cheng, et al. also provided a prediction of coolant density along the length of the fuel assembly produced by a TRACE/PARCS coupled model of a BWR [27]. Figure 6 shows that prediction in comparison to the CTF prediction for Simulation 1 and 2. 


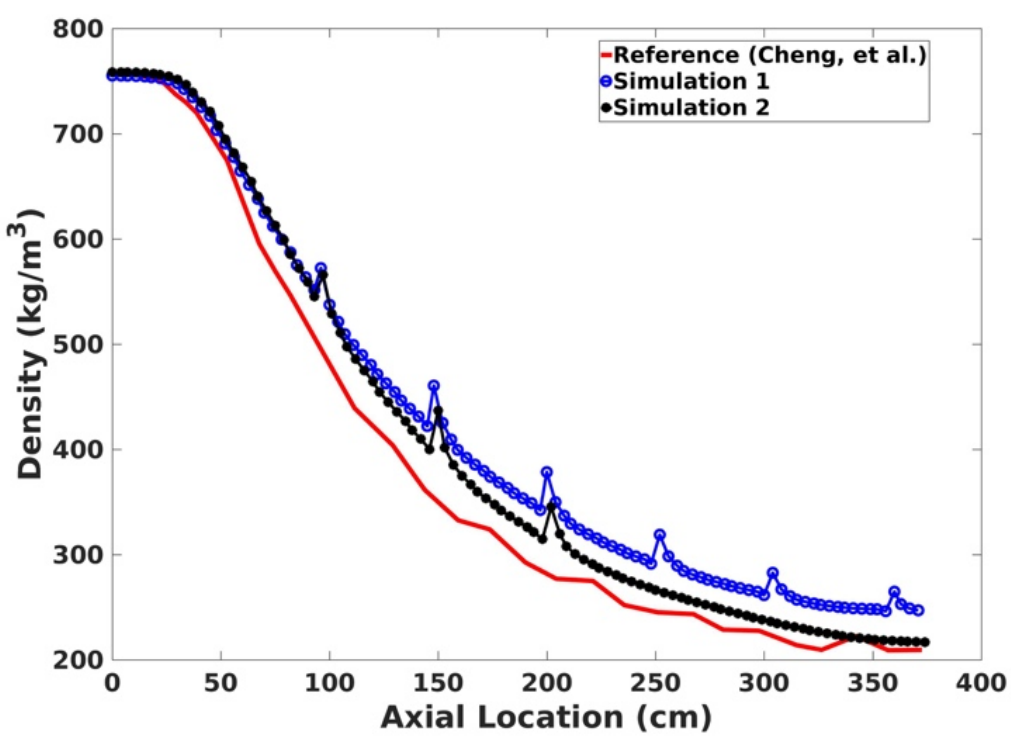

Figure 7: Axial variation of coolant density in the fuel assembly.

Although Simulation 2 has initial conditions based on the Cheng, et al. report [27], it is unknown if the geometry and power profiles used by Cheng, et al. differ from what was used in Simulation 2. Again, the sudden changes in density are due to spacer grids in Simulation 1 and 2, which were not present in the reference model.

Simulation 1 had a pressure drop of 1.156 bar across the assembly length, and Simulation 2 had pressure drop of 1.181 bar. The expected pressure drop was anticipated to be in the range of 0.758 bar to 1.689 bar, with the lower limit corresponding to the reported pressure drop across an ESBWR fuel assembly and the upper limit corresponding to the pressure drop across a GE11 fuel assembly as predicted by Ferroni [23]. The reported pressure drops for Simulation 1 and 2 occur when the surface roughness of the $\mathrm{SiC}$-SiC channel box was set to $20 \mu \mathrm{m}$, which is representative of as-manufactured nuclear-grade SiC$\mathrm{SiC}$ [29]. Terrani, et al. [6] found that, when oxidized in steam, the average surface roughness of SiC-SiC may be as high as $54 \mu \mathrm{m}$. To determine the effect that higher surface roughness would have on pressure drop, the surface roughness of the channel box was varied from $2.5 \mu \mathrm{m}$ (which is characteristic of zircaloy) to $60 \mu \mathrm{m}$. The resulting variation in pressure drop is shown in Figure 7 with designations as to what surface roughness range corresponds to zircaloy and SiC-SiC. The predicted pressure drop variation was small and had a negligible effect on the results pertinent to this study. 


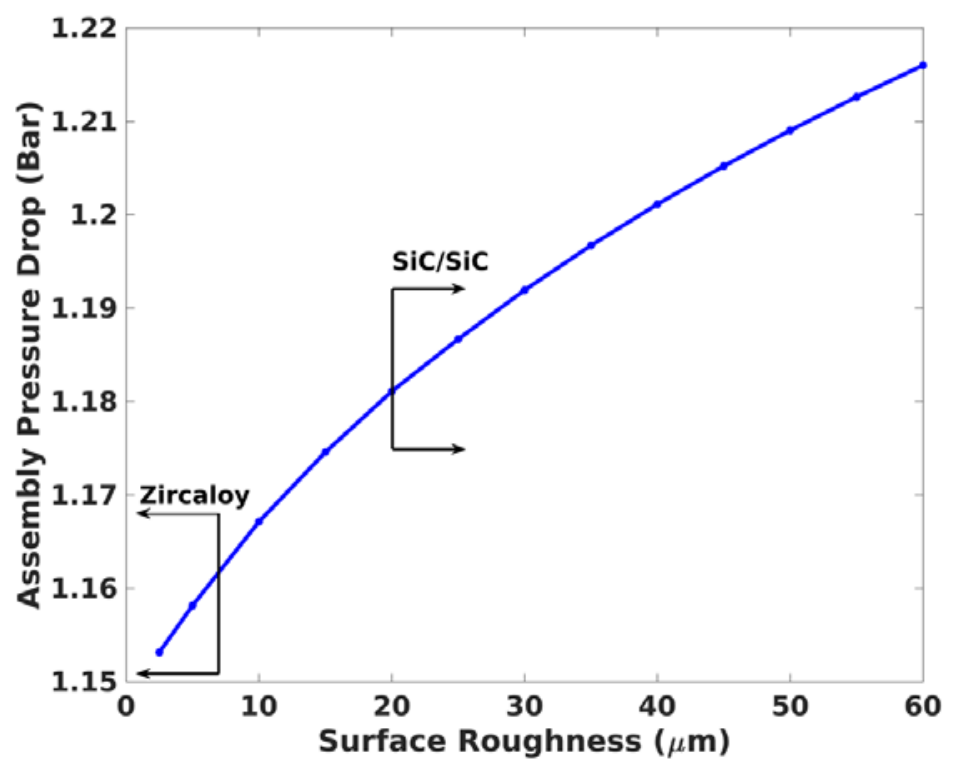

Figure 8: Effect of channel box surface roughness on assembly pressure drop.

Although assembly average axial power profiles were found in the literature, an axial relative power distribution was calculated for each of the 92 rods in the assembly using Serpent 2 to account for radial variations. To verify that the power profiles calculated using Serpent 2 are representative, Figure 8 provides a comparison between the assembly average axial power profiles obtained from the literature and the average of the 92 calculated axial power profiles. Based on the general agreement of the average power profiles shown, the calculated axial profiles are reasonable and representative.
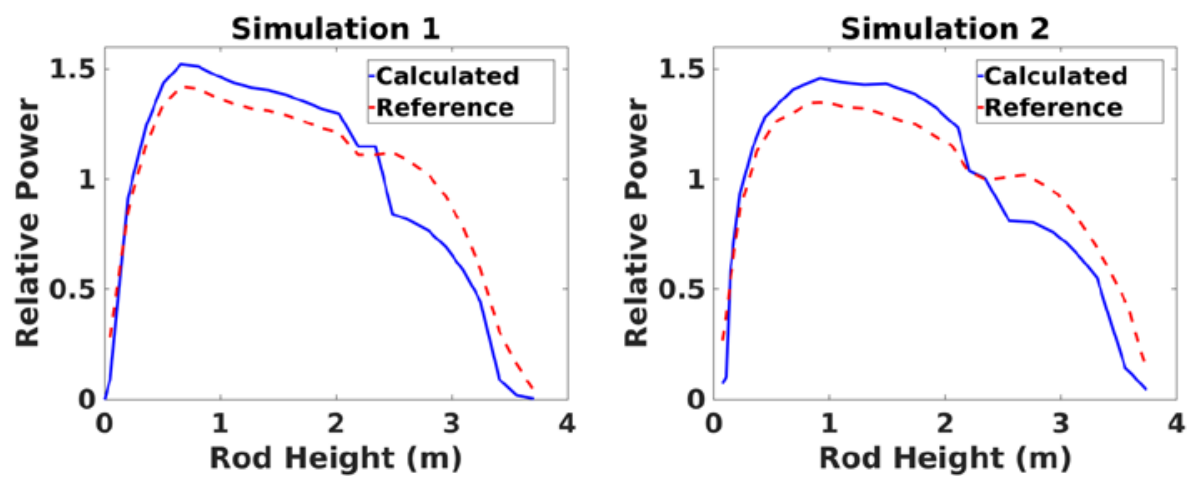

Figure 9: Comparison between calculated and reference average axial power profiles.

Additionally, a check was performed to ensure that the power input into the system was equivalent to the output power calculated by CTF. The Simulation 1 output power was within $0.002 \%$ of the power input into the system, and the Simulation 2 output power was within $0.07 \%$ of the power input into the system.

\section{Resultant Flux and Temperature Boundary Conditions}

Figures 9 and 10 show the CTF-predicted spatial temperature distributions within the channel box for Simulation 1 and Simulation 2, respectively. Each of the four sides of the channel box are shown in the figures. 

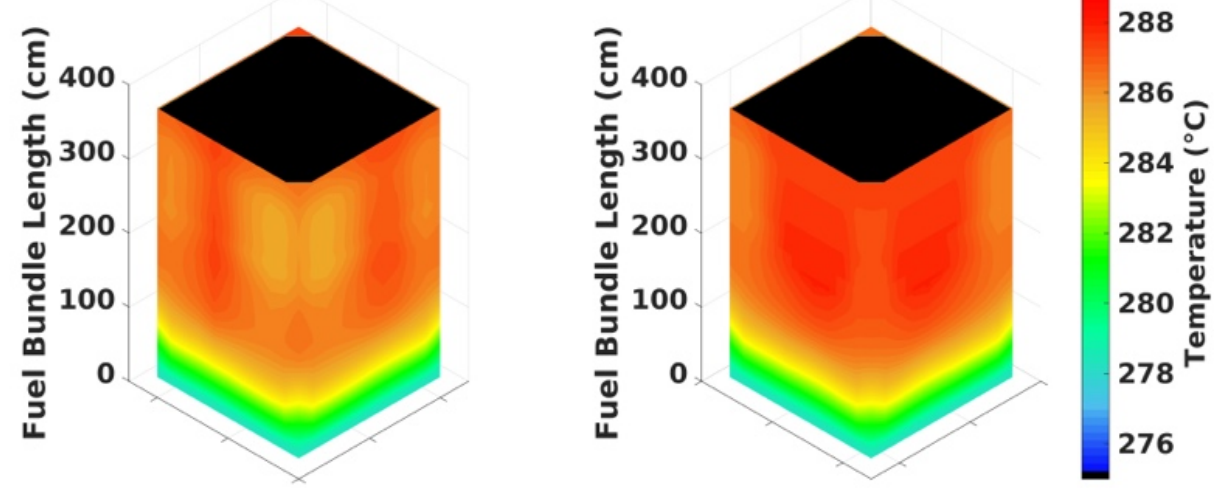

Figure 10: Spatial temperature distribution of the channel box in Simulation 1.
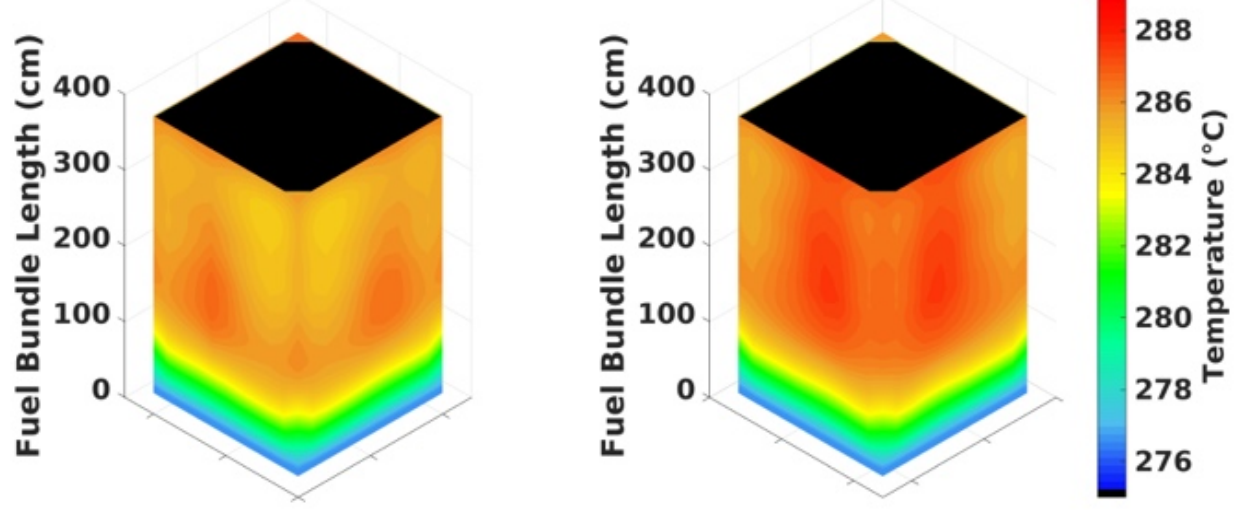

Figure 11: Spatial temperature distribution of the channel box in Simulation 2.

The channel box temperature in each simulation ranges from the inlet temperature of the coolant to a maximum of approximately $288^{\circ} \mathrm{C}$. There is significant azimuthal variation in the channel box temperature around the periphery due to the variation of fuel enrichments and relative power factors throughout the assembly.

The spatial distribution of neutron flux calculated by Serpent 2 are shown in Figures 11 and 12, respectively. These figures show the flux for neutron energies greater than $0.1 \mathrm{MeV}$. Again, all four faces of the channel box are shown. 

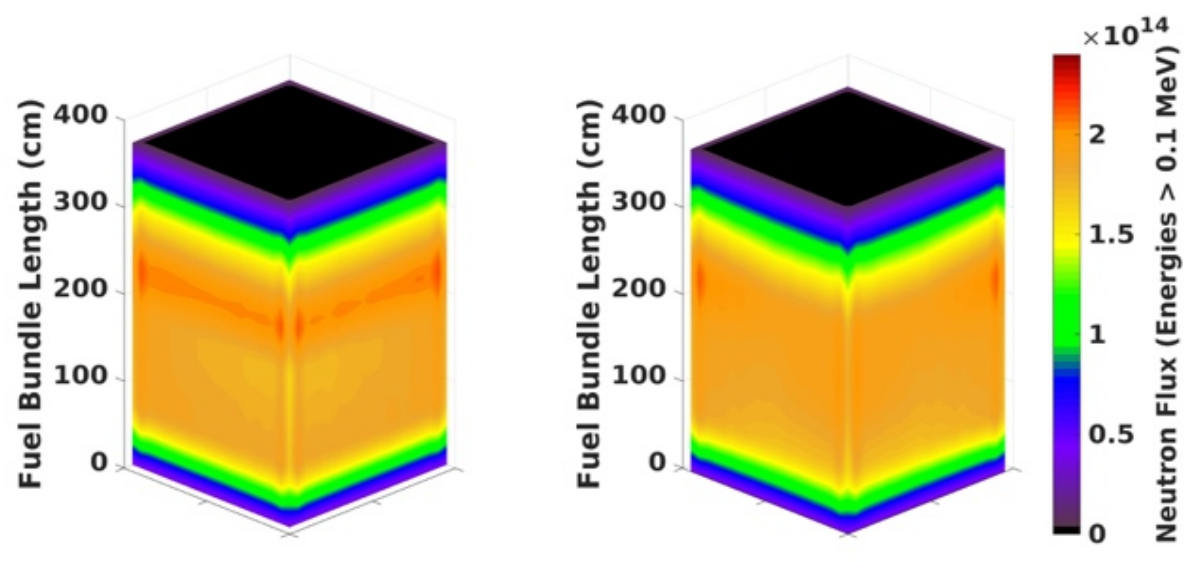

Figure 12: Spatial distribution of fast flux in the channel box for Simulation 1.
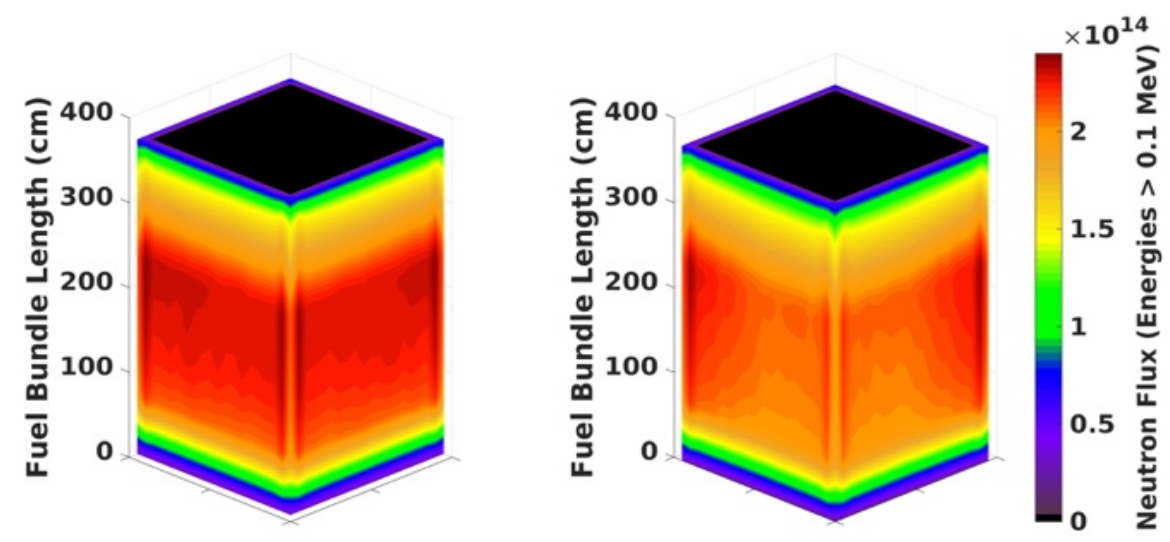

Figure 13: Spatial distribution of fast flux in the channel box for Simulation 2.

A maximum fast flux of about $2.2 \times 10^{14}$ neutrons $/ \mathrm{cm}^{2}$-s is predicted for the Simulation 1 channel box, while a maximum fast flux of $2.4 \times 10^{14}$ neutrons $/ \mathrm{cm}^{2}$-s is seen in the Simulation 2 channel box consistent with the higher power.

\subsection{Lateral Displacement}

$\mathrm{SiC}$ channel box displacement analysis was performed using the commercial Abaqus software as well as the INL developed BISON code based on the calculated temperature and flux boundary conditions described in section 3.1. In this section, the results of the Abaqus analysis are presented, and the next section will present a comparison between the two codes. Figure 13 shows the contour plots of displacement in $\mathrm{x}$-direction (perpendicular to wall). Figure 14 shows the variation in the total lateral displacement of the channel box with time. 


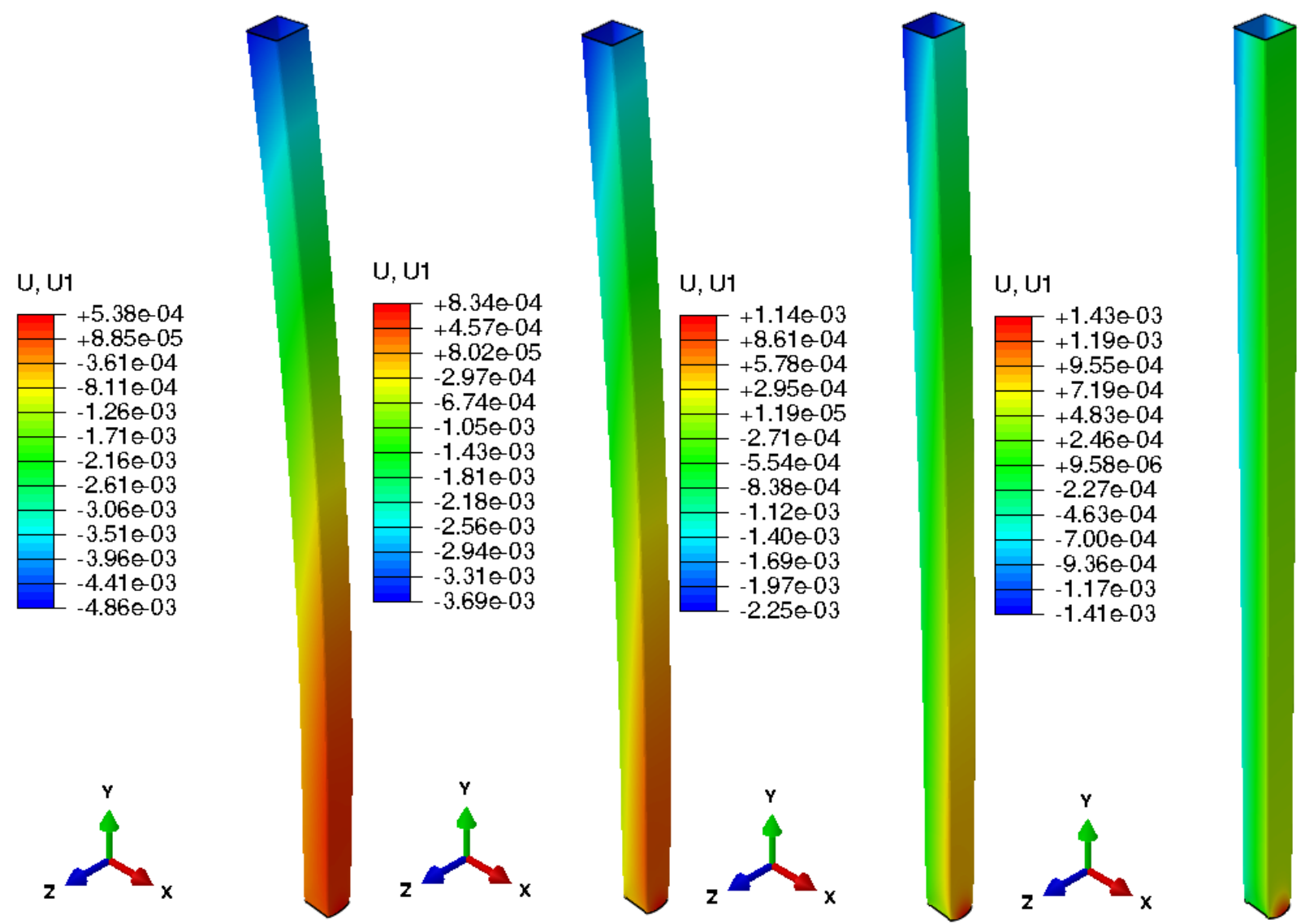

Figure 14: Displacement (units: meter) of the channel box along the $x$-direction (perpendicular to wall) after 11 days, one month, two months and four months (from left to right). Displacement is exaggerated for visualization purpose. The total displacement is shown in Figure 14.

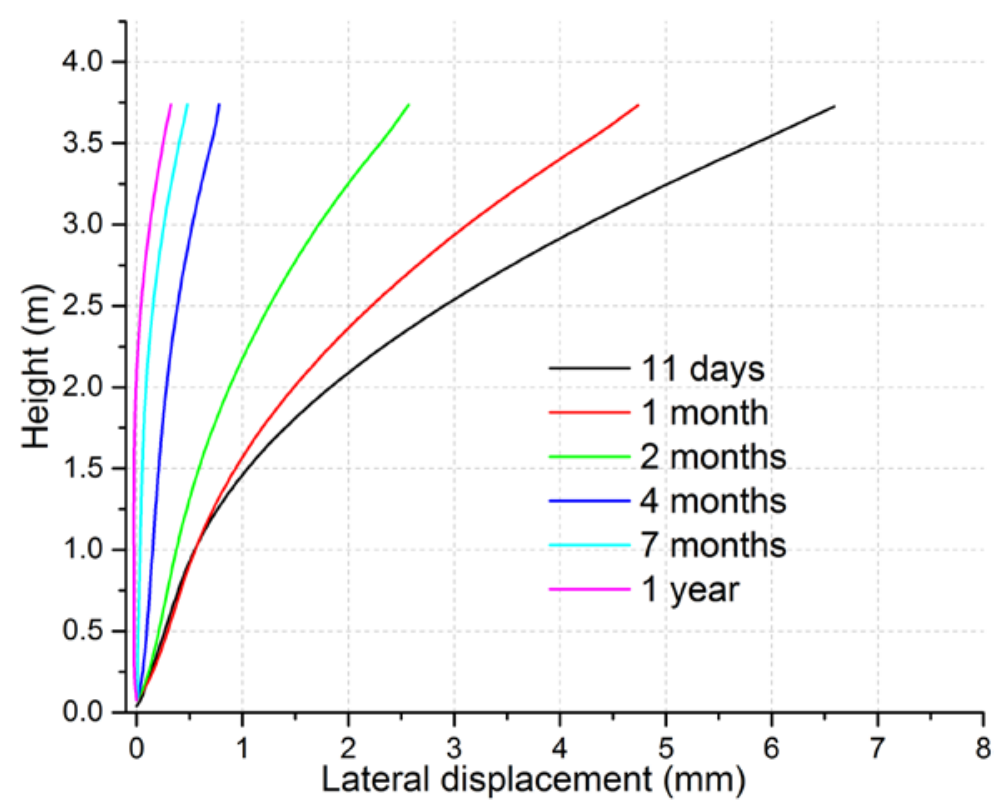

Figure 15: Total lateral displacement (in the diagonal direction) versus channel box height at different operating times. 
The channel box initially undergoes fairly significant lateral bending until about 11 days, driven primarily by the neutron flux gradients and the corresponding irradiation temperature dependent swelling. The bending occurs rapidly and leads to a maximum lateral displacement of $6.8 \mathrm{~mm}$. The high bending rate can be attributed to the rapid swelling of $\mathrm{SiC}$-SiC across the width of the channel box due to neutron irradiation, as shown in Figure 1. This behavior will be discussed in more detail in the following section. As noted in Figures 11 and 12, the neutron fast flux varies by an order of magnitude across the channel box and this leads to non-uniform swelling, which ultimately produces the lateral displacement of the channel box. The increase in neutron fluence following reactor startup leads to differential swelling across the width of the channel box that initially increases with time, until a maximum displacement of the channel box is predicted to occur at about 11 days.

After 11 days, the SiC swelling begins to saturate in those regions of the channel box which experience the largest fast flux, although the swelling magnitude is continuing to increase towards the saturation value (with decreasing swelling rate) in the lower flux regions. Thus, the differential swelling across the channel box begins to decrease as all regions reach the dose level consistent with saturated SiC swelling. This condition leads to a straightening of the channel box, or relaxation of the initial displacements. As the rate of swelling of the $\mathrm{SiC}$-SiC material decrease with fluence (Figure 1). the rate of decrease in differential swelling or the rate of straightening of the channel box also decreases with fluence/time. After about one year, the swelling in the entire channel box has reached the saturation values and much of the flux dependent deformation has relaxed. A temperature gradient of about $2.5^{\circ} \mathrm{C}$ across the channel box and since the saturated swelling is temperature dependent, the channel box has an unrecovered lateral displacement of $\sim 0.3 \mathrm{~mm}$ after one year.

\subsection{Model Comparison and Displacement Contributions}

As previously mentioned, the displacement analysis of the SiC channel box was performed using two codes, BISON and Abaqus, for the purpose of benchmarking the code predictions against each other. Figure 15 compares the predicted displacements from Abaqus versus BISON. Both codes use the same material models but different finite element solvers, and thus reasonable but not identical agreement is expected. The codes predict similar maximum displacement magnitudes of about $6.6 \mathrm{~mm}$ at 8.2 and 11 days for BISON and Abaqus, respectively. Both finite element codes predict an initial rapid bowing of the channel box as the reactor begins operation. The codes also confirm the relaxation of the channel box as the swelling begins to saturate. As well, the codes agree on the residual lateral displacement that persists after 1 year, and results from the saturated levels of the temperature dependence of SiC swelling. While there are some differences between the Abaqus and BISON models, good agreement in maximum displacement and the displacement evolution with neutron fluence was achieved. 


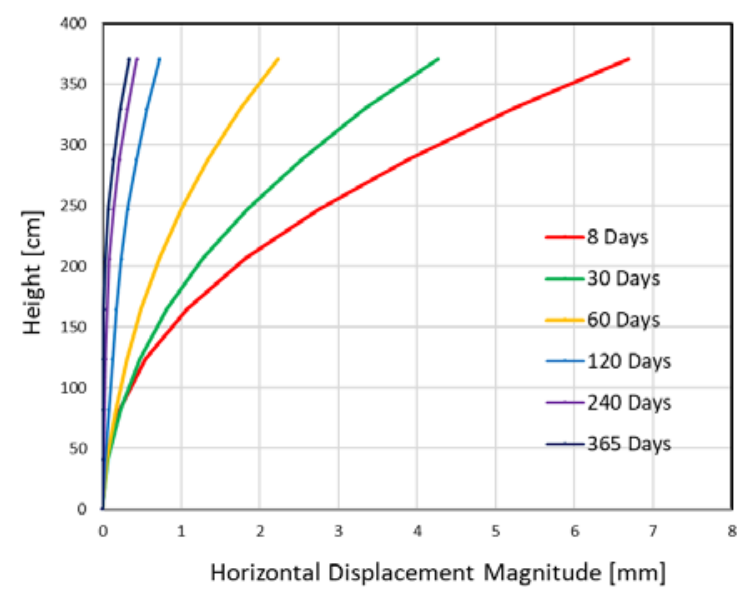

a)

Figure 16: Plots comparing the lateral displacement magnitude predicted by BISON (left) and Abaqus

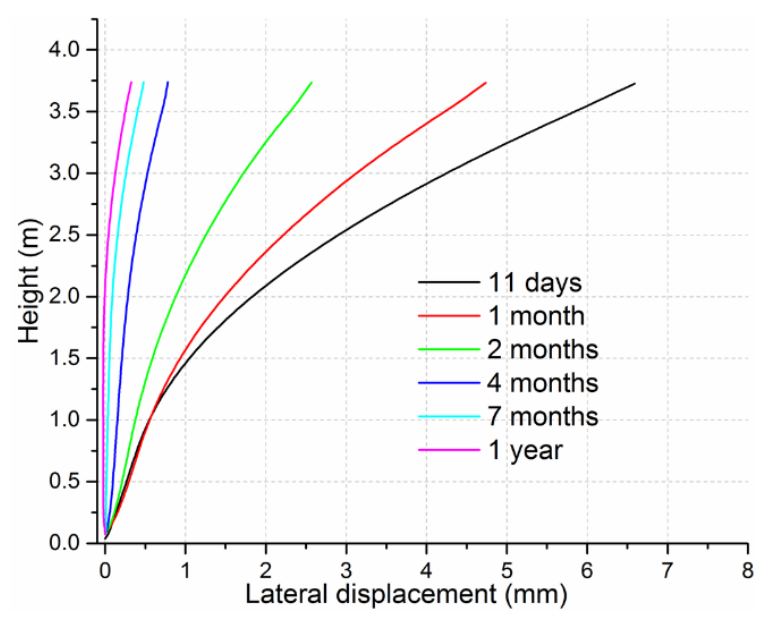
(right).

Figure 16 presents an analysis to determine the effects of individual contribution of thermal strain and irradiation induced swelling on the bowing displacement of the SiC-SiC channel box. For these simulations, each effect was individually disabled and the resulting horizontal displacements were compared. The walls of the channel box were designated as 1, 2, 3, and 4 moving clockwise around the channel box. The neutron flux is highest at the corner of walls 1 and 4, but is lowest diagonally opposite of the channel box at the corner of walls 2 and 3. This leads to displacements as a result of the neutron flux profile, which are diagonal to the channel box and towards walls 2 and 3. However, the temperature profile will produce displacements which are essentially square to the channel box and towards wall 1 , since wall 3 was somewhat hotter than the remaining surfaces.

Thermal expansion was considered first. Due to the small circumferential temperature variation of about $2.5^{\circ} \mathrm{C}$ on average, large lateral displacements are not expected from this effect. The model predicts that the absence of thermal expansion increased the maximum horizontal displacement by about $78 \mu \mathrm{m}$. Thermal strain gradient is opposite to the saturated swelling gradient as saturated swelling decreases with an increase in temperature. When thermal strains are turned off in the simulation, the total strain gradient across the channel box increases, and this results in an increase in the lateral displacement. A subsequent simulation to consider the effect of the temperature profile on the swelling behavior of the SiC material was performed, and an isothermal channel box at $267^{\circ} \mathrm{C}$ was simulated. The absence of a temperature gradient reduced the maximum horizontal displacement by $22 \mu \mathrm{m}$, and the residual displacement, after the swelling had saturated in the entire channel box, reduced by about $140 \mu \mathrm{m}$. This shows that the small temperature gradient present in the channel box does not make a significant contribution to the lateral bending.

Lastly, the swelling effect was disabled which led to significant reduction in the horizontal displacement. The predicted horizontal displacement under these conditions was about $0.1 \mathrm{~mm}$ which was due to the thermal gradients. This result shows that the channel box bowing is the result of the nonuniform neutron flux which generates differential swelling (and swelling rates) across the channel box which ultimately leads to significant lateral bowing. The higher flux level at the corner of wall 1 and 4 produces more rapid swelling that reaches saturation at earlier times than at the corner of walls 2 and 3, which results in the bowing displacement reaching a maximum early in the simulation. However, as the SiC swelling saturates, similar swelling levels are reached circumferentially around the channel box, which reduces the circumferential swelling gradients, and correspondingly the bowing displacement is 
greatly reduced. Additionally, the effect of creep was also considered. It was found that the contribution of creep to the bowing behavior is insignificant.

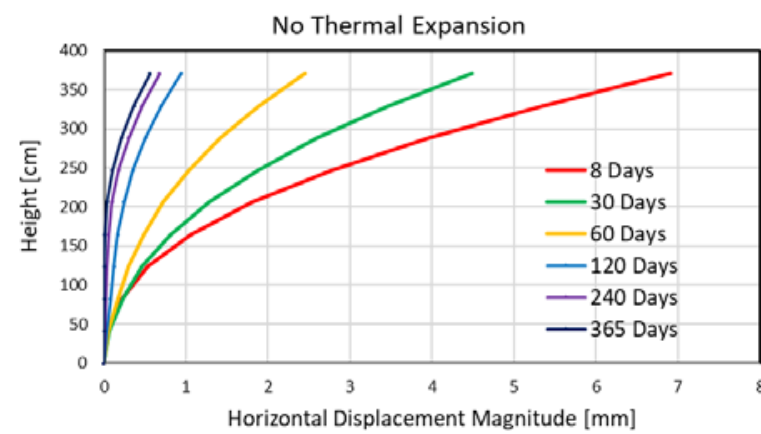

a)

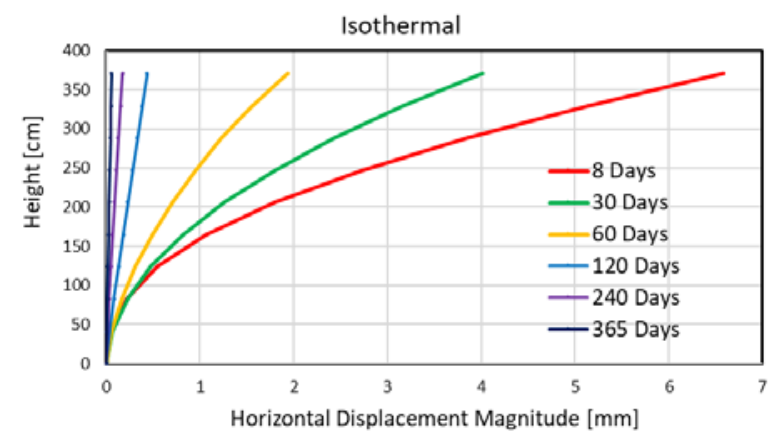

c)

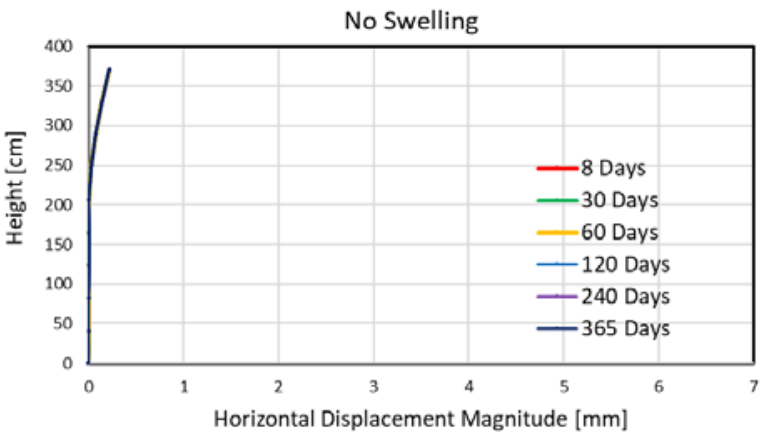

e)

Figure 17: Plots showing the effect on displacement from thermal expansion, temperature profile, and swelling (top to bottom). The plots on the right hand side indicate the corresponding differences, in which a positive difference indicates the effect induced additional lateral displacement, while negative values indicates a reduction in displacement. 


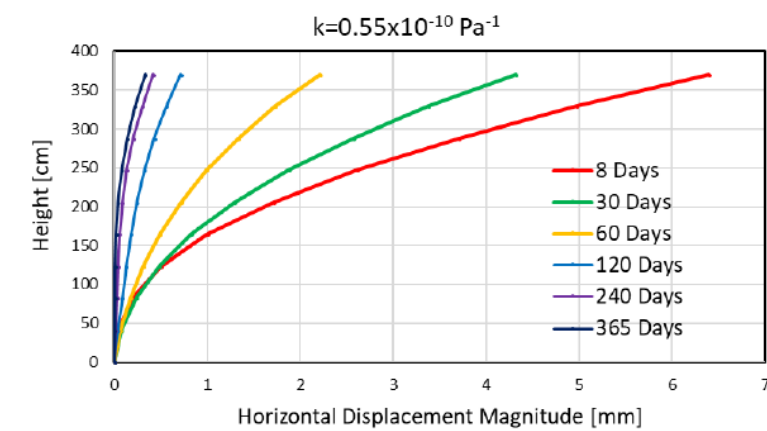

a)

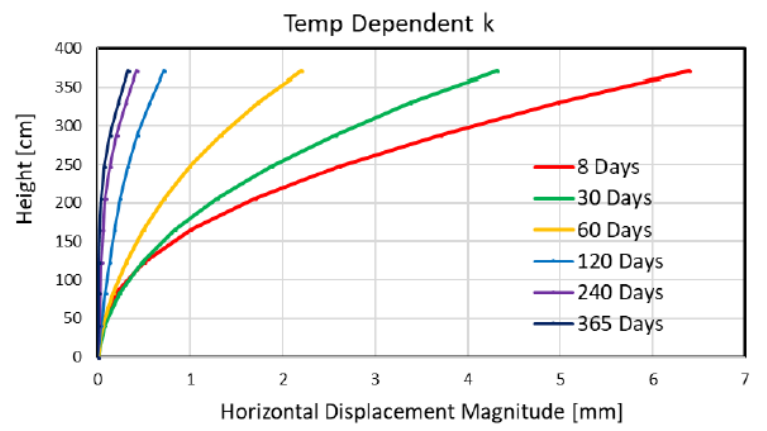

c)

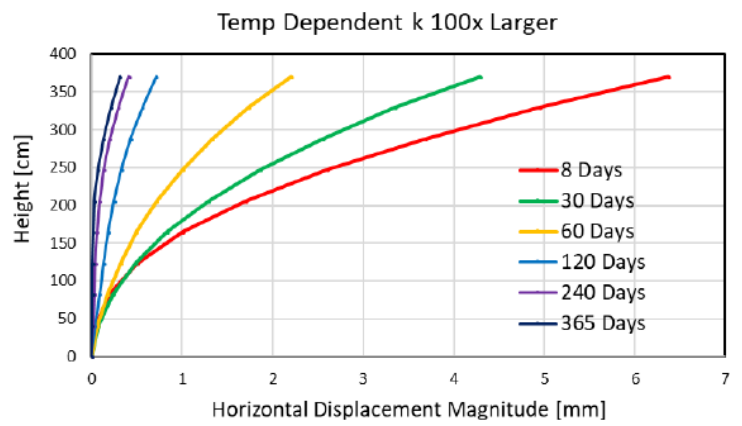

e)

Figure 18: Plots showing the effect of the irradiation creep model of $\mathrm{SiC}$ on channel box displacement (plots on the left side). The plots on the right side indicate the corresponding differences to the base model. a) and $b$ ) Compare the effect of creep using a temperature independent creep constant; c) and d) Compare the effect of creep using a temperature dependent creep constant; and e) and f) Compare the effect of creep using a 100X increase in the creep constant.

As well, we have evaluated the influence of irradiation creep on the results. The thermal creep in SiC is negligible below $1400^{\circ} \mathrm{C}$ [30], so only irradiation creep is considered. The creep sensitivity study was performed using isotropic elasticity properties of SiC-SiC due to difficulties in implementing creep along with the anisotropic model in BISON. A coupled creep-swelling model of the form $\varepsilon^{\mathrm{c}}=\mathrm{k} \dot{\varepsilon_{\mathrm{v}}} \bar{\sigma}$, where $\mathrm{k}$ is the creep constant, $\dot{\varepsilon}_{\mathrm{v}}$ is the volumetric swelling rate, and $\bar{\sigma}$ is the stress tensor has been implemented. Figure 17a and $\mathrm{b}$ show the effect of including creep using a constant $\mathrm{k}=5.5 \times 10^{-11} \mathrm{~Pa}^{-1}$. The resulting difference in displacement is less than $10 \mu \mathrm{m}$ in comparison to the case with no creep strain included. Figure 17c and d show the results using a temperature dependent creep constant [18] and the results are very similar to Figures $17 \mathrm{a}$ and b. Finally, the creep constant (k) was multiplied by a factor of 100 and Figure $17 \mathrm{e}$ and $17 \mathrm{f}$ show the predicted impact on the channel box displacement. Again, in Fig. 17e, the qualitative trend is very similar, and as shown in Fig. 17f, the difference in the lateral displacement is less 
than $50 \mu \mathrm{m}$, even with a $100 \mathrm{X}$ increase in the irradiation creep rates, when compared to the case with no creep strain. Thus, we conclude that the contribution of irradiation creep to the bowing behavior is relatively insignificant.

\section{CONCLUSIONS}

The work presented here describes the results of a the preliminary analysis to determine the displacements of SiC-SiC channel box without control blade insertion using either the fuel performance code BISON or the commercial finite element code Abaqus. The neutron flux and temperature boundary conditions were calculated using the Serpent2 and COBRA-TF neutronics and thermal-hydraulics codes, respectively. The following conclusions can be drawn from this work:

1) SiC-SiC channel box will undergo significant lateral bending (greater than $6.5 \mathrm{~mm}$ ) during initial reactor operation. This level of lateral displacement of the channel box raises concerns about the smooth insertion of the control blades.

2) Large gradient in the neutron flux across the channel box, which lead to significant differential swelling in the channel, is the primary cause of the channel box distortion. It may be noted the SiC-SiC cladding is also expected to undergo lateral bending [10]. However, in the case of SiC cladding it is the non-uniform temperature along the circumference which is the primary cause of bending.

3) The lateral bending of the channel box decreases throughout reactor operation leading to straightening of the channel box. The rate of bending is fast initially and diminishes gradually.

4) The relaxation of bending is not fully complete and a small residual bending $(\sim 0.3 \mathrm{~mm})$ is expected to remain even when the swelling has fully saturated in the entire channel box after about an year. This residual bending exists due the small temperature gradients of about $2.5^{\circ} \mathrm{C}$ across the channel. It may be noted that in case of $\mathrm{SiC}$ cladding, the residual bending is much greater ( few millimeters) [10].

The control blade insertion can generate much sharper neutron flux gradients in a channel box than those without control blade insertion as was considered in the analysis presented here. This work has set the stage for a more thorough deformation analysis of the SiC-SiC channel box with control blade insertion to different heights that will lead to improved understanding about the viability of SiC-SiC channel box for BWR applications. 


\section{REFERENCES}

1. Kawasaki, S., T. Furuta, and M. Suzuki, Oxidation of Zircaloy-4 under high temperature steam atmosphere and its effect on ductility of cladding. Journal of nuclear science and technology, 1978. 15(8): p. 589-596.

2. Urbanic, V. and T. Heidrick, High-temperature oxidation of zircaloy-2 and zircaloy-4 in steam. Journal of nuclear materials, 1978. 75(2): p. 251-261.

3. Yueh, K. and K.A. Terrani, Silicon carbide composite for light water reactor fuel assembly applications. Journal of Nuclear Materials, 2014. 448: p. 380-388.

4. Katoh, Y., et al., Stability of SiC and its composites at high neutron fluence. Journal of Nuclear Materials, 2011. 417(1-3): p. 400-405.

5. Hasegawa, A., et al., Critical issues and current status of SiC/SiC composites for fusion. Journal of Nuclear Materials, 2000. 283-287: p. 128-137.

6. Terrani, K.A., et al., Silicon Carbide Oxidation in Steam up to $2 \mathrm{MPa}$. Journal of American Ceramic Society, 2014. 97(8): p. 2331-2352.

7. Avincola, V.A., et al., Oxidation at high temperatures in steam atmosphere and quench of silicon carbide composites for nuclear application. Nuclear Engineering and Design 2015. 295: p. 468-478.

8. Katoh, Y., et al., Continuous SiC fiber, CVI SiC matrix composites for nuclear applications: Properties and irradiation effects. Journal of Nuclear Materials, 2014. 448: p. 448-476.

9. Garzarolli, F., et al., BWR Fuel Channel Distortion. Advanced Nuclear Technology International, 2011.

10. Singh, G., et al., Parametric Evaluation of SiC/SiC Composite Cladding with UO2 Fuel for LWR Applications: Fuel Rod Interactions and Impact of Nonuniform Power Profile in Fuel Rod. Journal of Nuclear Materials, 2018. 499: p. 155-167.

11. Salko, R.K., R.C. Schmidt, and M.N. Avramova, Optimization and parallelization of the thermal-hydraulic subchannel code CTF for high-fidelity multi-physics applications. Annals of Nuclear Energy, 2015. 84: p. 122-130.

12. Leppänen, J., Serpent-a continuous-energy Monte Carlo reactor physics burnup calculation code. VTT Technical Research Centre of Finland, 2013. 4.

13. Williamson, R., et al., Multidimensional multiphysics simulation of nuclear fuel behavior. Journal of Nuclear Materials, 2012. 423(1): p. 149-163.

14. Abaqus, V., 6.14 Documentation. Dassault Systemes Simulia Corporation, 2014.

15. Snead, L.L., et al., Handbook of SiC properties for fuel performance modeling. Journal of Nuclear Materials, 2007. 371(1-3): p. 329-377.

16. Byun, T.S., et al., Influence of specimen type and loading configuration on the fracture strength of sic layer in coated particle fuel. Ceramics in Nuclear and Alternative Energy Applications, Ceramic Engineering and Science Proceedings, Cocoa Beach, 2009. 310: p. 77.

17. Singh, G., K. Terrani, and Y. Katoh, Thermo-mechanical assessment of full SiC/SiC composite cladding for LWR applications with sensitivity analysis. Journal of Nuclear Materials, 2018. 499: p. 126-143.

18. Katoh, Y., et al., Observation and possible mechanism of irradiation induced creep in ceramics. Journal of Nuclear Materials, 2013. 434(1): p. 141-151.

19. Hegeman, J., et al., Mechanical and thermal properties of SiC f/SiC composites irradiated with neutrons at high temperatures. Fusion engineering and design, 2005. 75: 
p. 789-793.

20. Katoh, Y., Final Report on Irradiation of Bonded-fiber SiC Composite, ORNL/TM2012/201, Oak Ridge National Laboratory. 2010.

21. Singh, G., et al., Interlaboratory Round Robin Study on Axial Tensile Properties of SiCSiC CMC Tubular Test Specimens. International Journal of Applied Ceramic Technology. doi: 10.1111/ijac.13010, 2018.

22. GE. [cited 2018; Available from: https://nuclear.gepower.com/fuel-a-plant/products/ge14.

23. Ferroni, P., Steady state thermal hydraulic analysis of hydride fueled BWRs. 2006, Massachusetts Institute of Technology.

24. Glück, M., Validation of the sub-channel code F-COBRA-TF: Part I. Recalculation of single-phase and two-phase pressure loss measurements. Nuclear Engineering and Design, 2008. 238(9): p. 2308-2316.

25. DeFilippis, M. and G. R. Higgins, E14 Fuel Assembly Mechanical Design Report. Global Nuclear Fuel Licensing Topical Report, 2005. NEDO-33236.

26. Fensin, M.L., Optimum Boiling Water Reactor Fuel Design Strategies to Enhance Reactor Shutdown by the Standby Liquid Control System. 2004, University of Florida.

27. Cheng, L., BWR Anticipated Transients Without Scram in the MELLLA+ Expanded Operating Domain-Events Leading to Emergency Depressurization. 2012, BNL-985842012-IR*, Brookhaven National Laboratory.

28. Inoue, A., et al., Void fraction distribution in BWR fuel assembly and evaluation of subchannel code. Journal of Nuclear science and Technology, 1995. 32(7): p. 629-640.

29. Colombo, P., et al., Joining of SiC/SiCf ceramic matrix composites for fusion reactor blanket applications. Journal of Nuclear Materials, 2000. 278(2-3): p. 127-135. 